\title{
A Double Sky-Hook Algorithm for Improving Road-Holding Property in Semi-Active Suspension Systems for Application to In-Wheel Motor
}

\author{
Seunghoon Woo ${ }^{1}$ and Donghoon Shin ${ }^{2, *}$ (D) \\ 1 R\&D Division, Hyundai Motor Company, Onseokdong Hwaseongsi, Seoku-dong, Hwaseong-si 18280, Korea; \\ boltra@naver.com \\ 2 Department of Mechanical Systems Engineering, Sookmyung Women's University, Seoul 04310, Korea \\ * Correspondence: dhshin@sookmyung.ac.kr; Tel.: +82-2-710-9154
}

check for updates

Citation: Woo, S.; Shin, D. A Double Sky-Hook Algorithm for Improving Road-Holding Property in

Semi-Active Suspension Systems for Application to In-Wheel Motor. Appl. Sci. 2021, 11, 8912. https://doi.org/ 10.3390/app11198912

Academic Editors: Flavio Farroni,

Andrea Genovese and

Aleksandr Sakhnevych

Received: 5 September 2021

Accepted: 21 September 2021

Published: 24 September 2021

Publisher's Note: MDPI stays neutral with regard to jurisdictional claims in published maps and institutional affiliations.

Copyright: (c) 2021 by the authors. Licensee MDPI, Basel, Switzerland. This article is an open access article distributed under the terms and conditions of the Creative Commons Attribution (CC BY) license (https:// creativecommons.org/licenses/by/ $4.0 /)$.
Featured Application: Double Sky-Hook Algorithm, Vehicle Dynamics and Control, Semi-Active Suspension Systems, In-Wheel Motor.

\begin{abstract}
This paper presents a double sky-hook algorithm for controlling semi-active suspension systems in order to improve road-holding property for application in an in-wheel motor. The main disadvantage of the in-wheel motor is the increase in unsprung masses, which increases after shaking of the wheel, so it has poor road-holding that the conventional theoretical sky-hook algorithm cannot achieve. The double sky-hook algorithm uses a combination of damper coefficients, one from the chassis motion and the other from the wheel motion. Computer simulations using a quarter and full car dynamic models with the road conditions specified by ISO2631 showed the effectiveness of the algorithm. It was observed that the algorithm was the most effective in the vicinity of the wheel hop frequency. This paper also proposed the parameter set of the double sky-hook algorithm to differentiate the driving mode of vehicles under advanced development.
\end{abstract}

Keywords: sky-hook; in-wheel motor; semi-active suspension

\section{Introduction}

In the layout of electric vehicles, one of the most interesting aspect is represented by the use of four in-wheel electric motors. As the motor is directly inside the wheel, no powertrain is required, thus leading to the elimination of elements such as drive shafts, gearboxes, and differentials [1,2]. There are also other advantages: space inside the car can be enlarged, thus having more room for passengers and for the battery pack [2,3]. Since the in-wheel motor is installed at each wheel, it allows direct yaw moment control function using the active drive torque distribution to improve the handling and maneuverability of electric vehicles $[4,5]$. The main disadvantage of in-wheel motor is the increase in unsprung masses, which increases after wheel shake, so it has poor road-holding [2,3,6]. One of the most effective ways to reduce this resonance is controlling the damping characteristics. Among the many control algorithms for semi-active suspension systems, the sky-hook algorithm is known to be very effective in controlling the sprung mass resonance [7-13]. However, this algorithm is not effective in controlling the unsprung mass resonance, so that the road-holding property in the vicinity of wheel hop frequency is worse than that of the passive suspension [14-16]. The resonance of wheels is transferred with noise and vibration to the chassis through the suspension and steering systems [15]. In addition, the vehicle dynamic stability is degraded. An optimal control algorithm with a performance index in the frequency domain [17] may overcome this defect. However, an optimal control algorithm is not robust to the system parameter uncertainty and nonlinearities. Moreover, this algorithm needs information of every state, so the actual implementation of an optimal control algorithm is not practical. 
In order to overcome the above-mentioned problems, a practical double sky-hook algorithm was proposed [18], which can effectively control the unsprung mass resonance as well as the sprung mass resonance. The proposed algorithm utilizes an additional sky-hook damper in the wheel combined with a conventional sky-hook damper that is attached to a sprung mass. In other words, the damper coefficient in a real physical semi-active damper is adjusted according to the principle of the sky-hook algorithm not only in the vicinity of the sprung mass resonant frequency, but also in the vicinity of the unsprung mass resonant frequency. In the algorithm, hardware components such as a semi-active damper and a chassis vertical accelerometer and a relative distance sensor for the proposed algorithm are the same as those of the conventional sky-hook algorithm. However, average damping force transmitted to the sprung mass can be increased due to larger value of an additional sky-hook damper at unsprung mass, which in turn, will increase the sprung mass acceleration levels. Therefore, there has been a great deal of research on determining the contribution of the sky-hook damping at unsprung mass for a semi-active suspension system [19-21].

This paper focused on the robust trade-off performance of ride comfort and handling by guaranteeing ride quality in every driving situation regardless of the value of the skyhook damping coefficient at unsprung mass. For practical proof, trade-off performance analysis using cross-plot of RMS (root mean square) tire normal force variation, and RMS body acceleration using the proper model was used. The analysis was performed with the model of the in-wheel motored vehicle under development and with enough fidelity model for ride comfort simulation, which consists of actuator delay, suspension friction, and damper nonlinearity.

The rest of this paper is organized as follows. In Section 2, modeling of the suspension dynamics of a quarter and a full car is described. Section 3 explains the principle of the double sky-hook algorithm and suggests a design method to select suitable damping coefficients. In Section 4, computer simulations with a quarter and a full car suspension dynamics model are presented with a discussion of some the results for the purpose of comparison with a passive and the conventional sky-hook suspension system in the RMS of the suspension performance measures. Conclusions are made in the final section.

\section{Modeling of Suspension Dynamics}

For the purpose of comparison between the conventional sky-hook algorithm and the double sky-hook algorithm, this section briefly summarizes the conventional one as follows. The detailed representations of model have been stated in the Appendix A.

\subsection{Quarter Car Model}

A simple two degrees-of-freedom model was built to compare the frequency responses, as shown in Figure 1. The suspension force, $f_{s}$, is generated by spring, damper, and friction. The tire force, $f_{t}$, is calculated by tire stiffness and tire damping. The dynamic equations of the system [22] can be represented as:

$$
\begin{gathered}
m_{u} \ddot{z}_{u}-f_{s}+f_{t}=0 \\
m_{s} \ddot{z}_{s}-f_{s}=f_{z}
\end{gathered}
$$

\subsection{Full Car Model}

A full car dynamic model that had eight degrees-of-freedom including roll, pitch, heave, driver seat, and four wheel vertical motions was constructed in order to demonstrate a more realistic vehicle behavior, as shown in Figure 2. This dynamic model included the wheel-base filtering effect, roll resonance effect by anti-roll bar stiffness and chassis roll moment of inertia, suspension friction, and the driver seat suspension effect on the three measures of suspension performance. The dynamic equations of the system [22] are represented as

$$
m_{u f l} \ddot{z}_{u f l}-f_{s f l}+f_{t f l}=0
$$




$$
\begin{gathered}
m_{u f r} \ddot{z}_{u f r}-f_{s f r}+f_{t f r}=0 \\
m_{u r l} \ddot{z}_{u r l}-f_{s r l}+f_{t r l}=0 \\
m_{u r r} \ddot{z}_{u r r}-f_{s r r}+f_{t r r}=0 \\
m_{s} \ddot{z}_{s}+f_{s f l}+f_{s f r}+f_{s r l}+f_{s r r}=f_{z} \\
J_{\phi} \ddot{\phi}+L_{f}\left(f_{s f l}+f_{s f r}\right)-L_{r}\left(f_{s r l}+f_{s r r}\right)=\tau_{\phi} \\
J_{\theta} \ddot{\theta}+W_{l}\left(f_{s f l}+f_{s r l}\right)-W_{r}\left(f_{s f r}+f_{s r r}\right)=\tau_{\theta}
\end{gathered}
$$

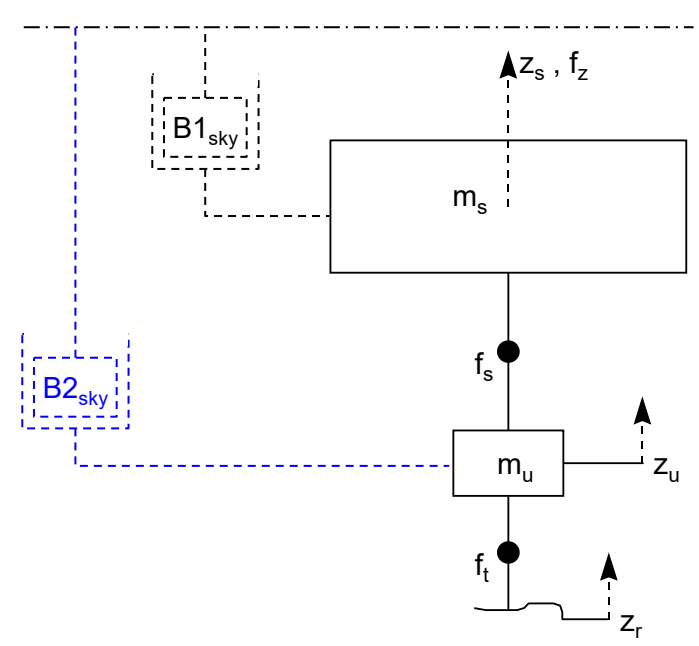

Figure 1. Quarter car model.

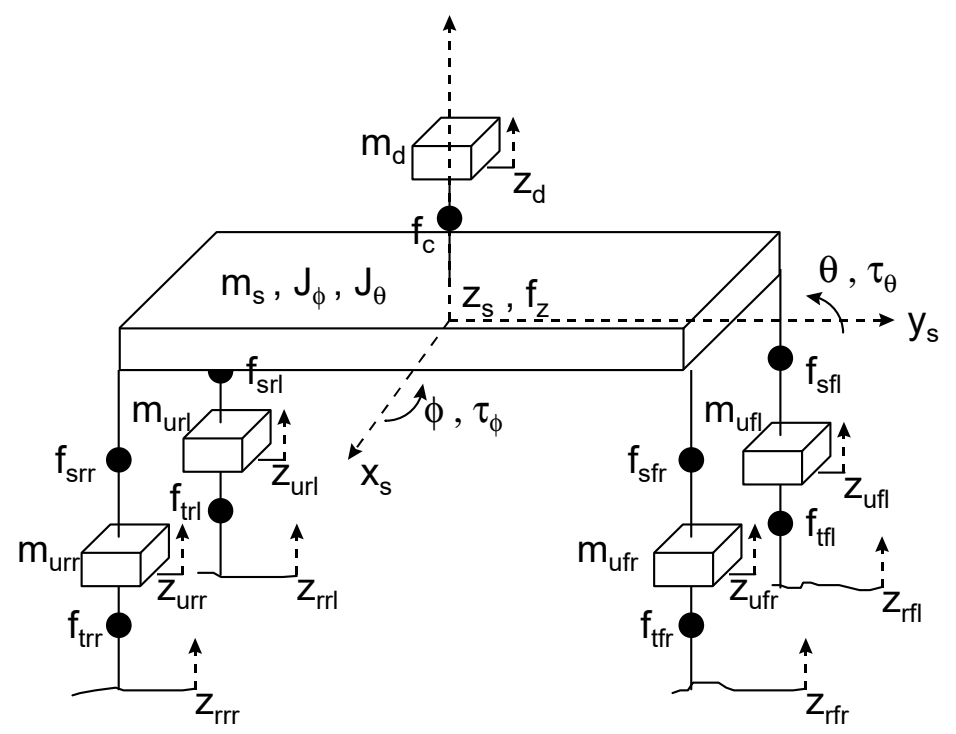

Figure 2. Full car model.

\section{Double Sky-Hook Control Algorithm}

\subsection{Conventional Sky-Hook Algorithm}

For the purpose of comparison between the conventional sky-hook algorithm and the double sky-hook algorithm, this section briefly summarizes the conventional one as follows: the force transmitted to the sprung mass through an ideal sky-hook damper is expressed as:

$$
F_{\text {sprung }}=B 1_{\text {sky }} \cdot \dot{x}_{s}
$$


where $B 1_{\text {sky }}$ is the sky-hook damping coefficient and $\ddot{x}_{s}$ is the sprung mass absolute vertical speed. In the real suspension configuration, however, the damping force is a function of a relative speed between a chassis and a wheel and is represented as

$$
F_{\text {sprung }}=B 1_{d} \cdot\left(\dot{x}_{s}-\dot{x}_{u}\right)
$$

where $\ddot{x}_{u}$ is the unsprung mass absolute vertical speed. The desirable damping coefficient $B 1_{d}$ that generates the same damping force as that of the ideal sky-hook damper is determined from Equations (1) and (2) as

$$
B 1_{d}=\frac{B 1_{s k y} \cdot \dot{x}_{s}}{\dot{x}_{s}-\dot{x}_{u}}
$$

As discussed in the introduction, this theoretic sky-hook damper is effective only in the vicinity of the sprung mass resonance frequency and has a worse road-holding property than that of a passive damper.

\subsection{Double Sky-Hook Algorithm}

Following the basic idea of the ideal sky-hook damper, if an additional sky-hook damper is attached to the unsprung mass in order to reduce the wheel hop resonance, the force transmitted to the unsprung mass through an ideal sky-hook damper is expressed as

$$
F_{\text {unsprung }}=B 2_{s k y} \cdot \dot{x}_{u}
$$

where $B 2_{\text {sky }}$ is the sky-hook damping coefficient. In the real suspension configuration, however, the damping force is a function of a relative speed between a chassis and a wheel and is represented as

$$
F_{\text {unsprung }}=B 2_{d} \cdot\left(\dot{x}_{u}-\dot{x}_{s}\right)
$$

The desired damping coefficient $B 2_{d}$ that generates the same damping force as that of the ideal sky-hook damper is determined from Equations (4) and (5) as

$$
B 2_{d}=\frac{B 2_{s k y} \cdot \dot{x}_{u}}{\dot{x}_{u}-\dot{x}_{s}}
$$

If we use the sky-hook damper only to the wheel, in other words, a real damping coefficient is adjusted by $B 2_{d}$, then the road-holding performance, which in turn, will greatly improve the vehicle dynamic stability.

Since a real semi-active suspension system is capable of controlling a single damping coefficient, however, we need to combine two damping coefficients $B 1_{d}$ and $B 2_{d}$ in such a way that both sprung and unsprung mass resonances are controlled effectively in each frequency region. For a simple combination, we propose the following combination as

$$
B_{d}=B 1_{d}+B 2_{d}
$$

Note that for a constant magnitude of relative velocity $\left(\dot{x}_{u}-\dot{x}_{s}\right), B 1_{d}$ in Equation (12) takes a large value in the sprung mass resonance frequency where the sprung mass vertical velocity is magnified dynamically while $B 2_{d}$ in Equation (15) takes a large value in the unsprung mass resonance frequency where the unsprung mass vertical velocity is magnified. Therefore, each damping coefficient is considered to play an effective role in each frequency region of interest.

In the case of Equation (16), the damping force transmitted is represented as

$$
F_{d}=B 1_{s k y} \cdot \dot{x}_{s}-B 2_{s k y} \cdot \dot{x}_{u}
$$

Then, the following four cases should be noted: 
Case I. If $B 2_{s k y}=0$, the algorithm behaves like a conventional ideal sky-hook algorithm where a sky-hook damper with a damping coefficient $B 1_{\text {sky }}$ is attached to a sprung mass.

Case II. If $0<B 2_{s k y}<B 1_{s k y}$, as the value of $B 2_{s k y}$ increases from zero when the value of $B 1_{s k y}$ is fixed, we expect better unsprung mass resonance control over the wheel hop frequency region. This will result in a decrease in the tire contact load variation (thus tire deflection). In this case, however, average damping force transmitted to the sprung mass will be increased due to the larger value of $B_{d}$, which in turn, will increase the sprung mass acceleration levels. Therefore, the selection of $B 2_{\text {sky }}$ for the fixed value of $B 1_{\text {sky }}$ should be made based on the relative importance between the sprung mass acceleration (ride quality) and the tire contact load variation (road-holding property: stability).

Case III. If $B 2_{s k y}=B 1_{s k y}$, then $F_{d}=B 1_{s k y} \cdot\left(\dot{x}_{s}-\dot{x}_{u}\right)$ from Equation (17). This case is equivalent to a passive damper with damping coefficient of $B 1_{\text {sky }}$.

Case IV. If $B 1_{s k y}=0$ or if $B 2_{s k y}>B 1_{s k y}$, then too large a damping force will be generated due to the fact that the vertical speed of the unsprung mass is usually far larger than that of the sprung mass. These cases will therefore degrade the ride quality significantly.

Step I. For a fixed trial value of $B 1_{s k y}$, which may be determined according to the conventional sky-hook theory, adjust $B 2_{s k y}$ from zero up to $B 1_{s k y}$ until the tire contact load variation in the vicinity of the wheel hop frequency is similar to that of a passive suspension. This adjustment is based on the fact that the larger the $B 2_{s k y}$, the greater the sprung mass acceleration to that of a passive suspension in the vicinity of the wheel hop frequency.

Step II. If $B 2_{s k y}$ is determined according to Step I while $B 1_{s k y}$ is fixed, we will obtain a sub-optimal damper in the wheel hop frequency region. However, overall damping coefficient will be increased so that the tire force variation and chassis acceleration will tend to be increased in-between sprung and unsprung mass resonant frequencies. However, three performance measures still became better than those of the conventional sky-hook algorithm in the sprung mass resonant frequency region. Therefore, we can reduce the value of $B 1_{s k y}$, which controls the suspension characteristics in the sprung mass resonant frequency region to a value where three performance measures were still better than those of the conventional sky-hook algorithm.

It was also noted that the range of a real adjustable damping coefficient is limited by physical hardware limits such as $B_{\min } \leq B_{d} \leq B_{\max }$.

\section{Simulation Studies}

\subsection{Simulation Conditions}

Computer simulation was performed to show the effectiveness and design procedure of the double sky-hook algorithm with a quarter and a full car suspension dynamic model. In this simulation, in order to include nonlinear behavior of actual semi-active suspension systems, we considered the dead time from an electronic circuit and a variable damper valve action as well as the ramp up time from the damping force development after the valve was closed. Figure 3 shows these time delays and its model using MATLAB Simulink. In addition, we included nonlinear characteristics of the damper, as shown in Figure 4. In the simulation, we used irregular random road profiles classified by the ISO [22]. Two different vehicle speeds with different road conditions were considered as follows:

Case (a): Grade A (Very Good), $S_{g}\left(\Omega_{0}\right)=4$ with $80 \mathrm{~km} / \mathrm{h}$

Case (b): Grade B (Very Poor), $S_{g}\left(\Omega_{0}\right)=256$ with $10 \mathrm{~km} / \mathrm{h}$ 


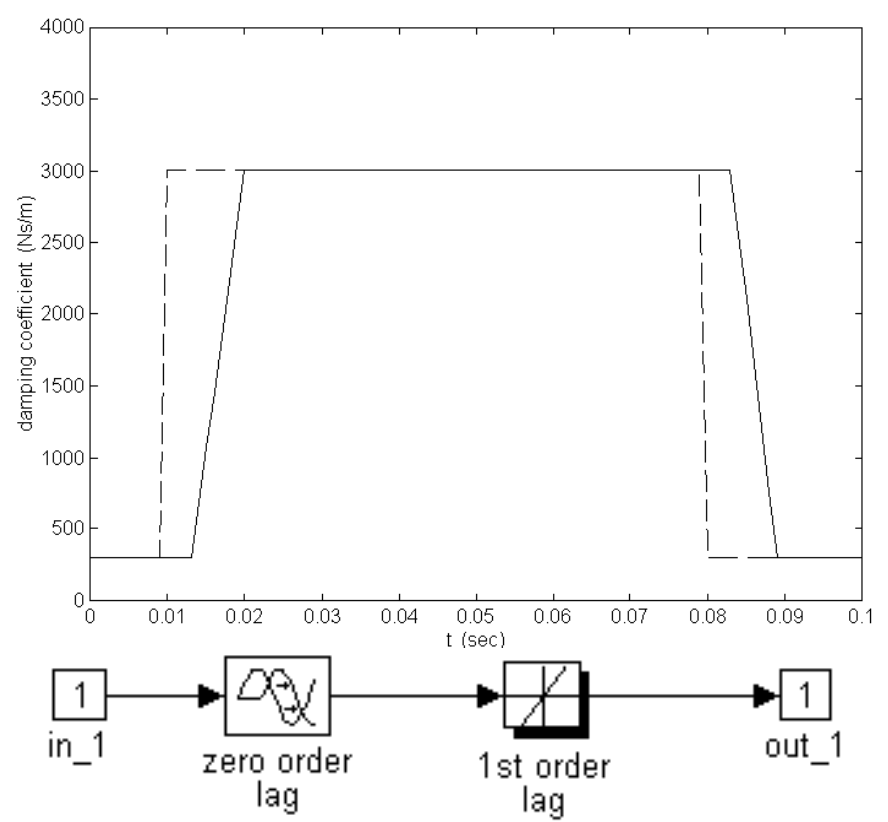

Figure 3. Time delay effect of variable damper (solid: with time delay, dashed: without time delay).

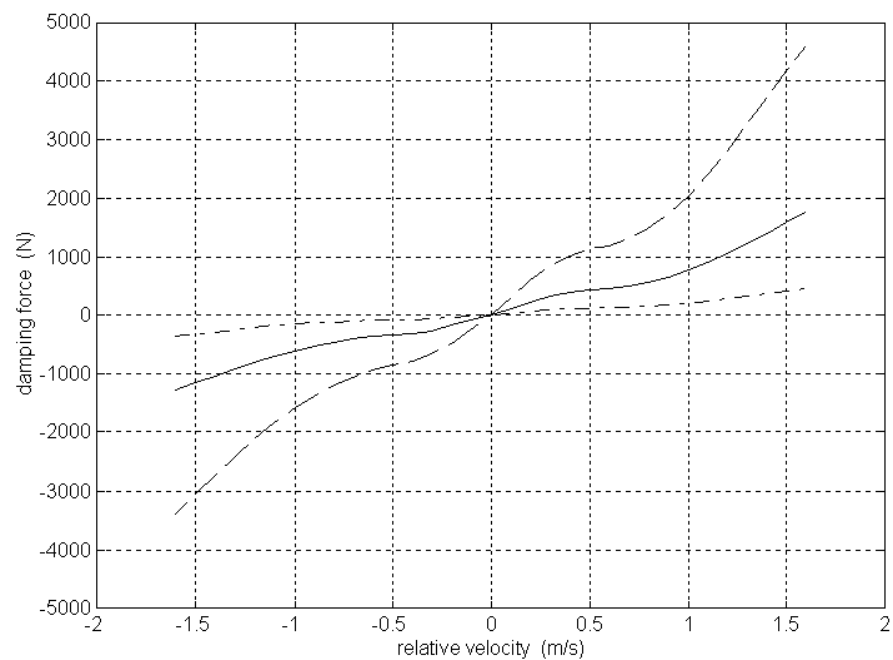

Figure 4. Nonlinear damping characteristics (solid: passive, dashed: max., dashdot: min.).

For the above simulation conditions, we simulated each vehicle dynamics model with a passive, conventional sky-hook, and double sky-hook damper.

\subsection{Quarter Car Model Simulation}

This quarter car model was selected to compare the frequency responses of three dampers. Table 1 shows the parameters of the quarter car model considering the in-wheel motor weight. The three suspension performance measures (chassis acceleration, tire force variation, suspension stroke) were evaluated by $1 / 3$ octave band RMS values on the frequency axis in Figures 5-7. In these figures, the solid line denotes the double sky-hook case, dashed line denotes the conventional sky-hook, and dash-dot line for passive damper. In these figures, case (a) is for smooth road profile with high speed and case (b) is for rough road profile with slow speed. 
Table 1. Model parameters for the quarter car.

\begin{tabular}{cc}
\hline Parameter & Value \\
\hline Effective weight of wheel $\left(m_{u}\right)$ & $85 \mathrm{~kg}$ \\
Weight of sprung mass $\left(m_{s}\right)$ & $563 \mathrm{~kg}$ \\
spring stiffness & $32,366 \mathrm{~N} / \mathrm{m}$ \\
Passive damper coefficient (effective) & $1577 \mathrm{Ns} / \mathrm{m}$ \\
Tire vertical stiffness & $248,000 \mathrm{~N} / \mathrm{m}$ \\
Tire vertical damping coefficient & $322 \mathrm{Ns} / \mathrm{m}$ \\
Max. damping coefficient & $3858 \mathrm{Ns} / \mathrm{m}$ \\
Min. damping coefficient & $300 \mathrm{Ns} / \mathrm{m}$ \\
Sky-hook damper on sprung mass $\left(B 1_{\text {sky }}\right)$ & $18,015 \mathrm{Ns} / \mathrm{m}$ \\
\hline
\end{tabular}

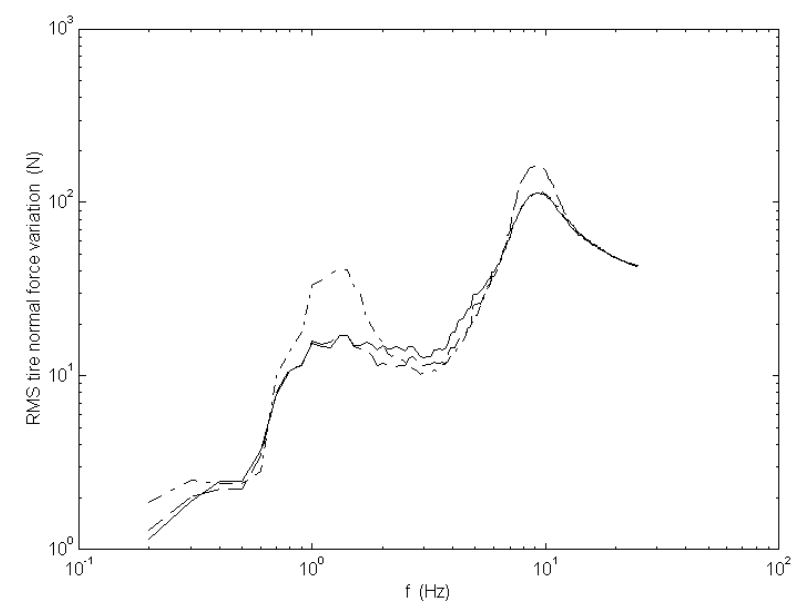

(a)

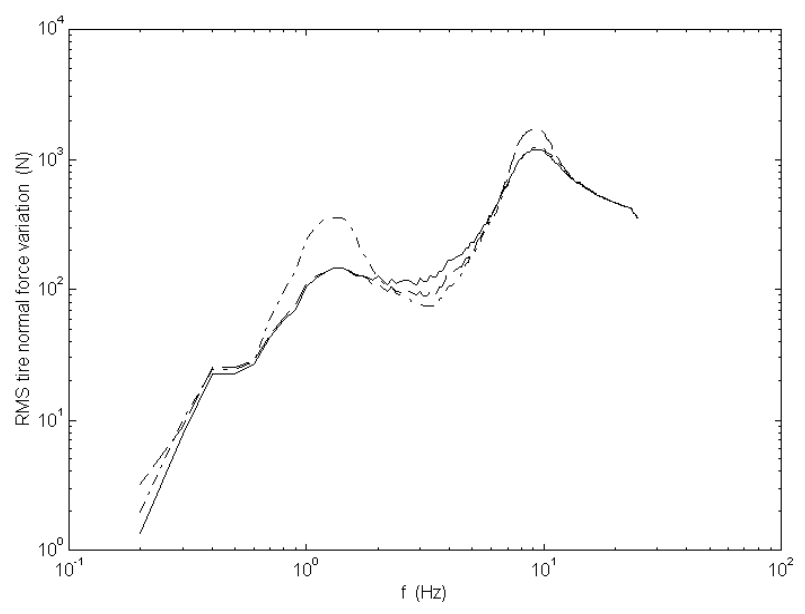

(b)

Figure 5. RMS of the tire normal force variation. (a) smooth road; (b) rough road.

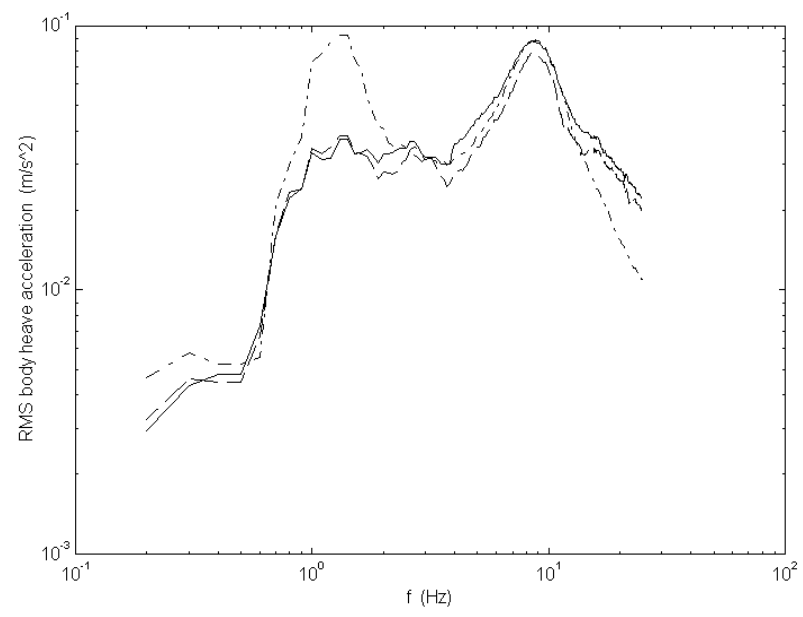

(a)

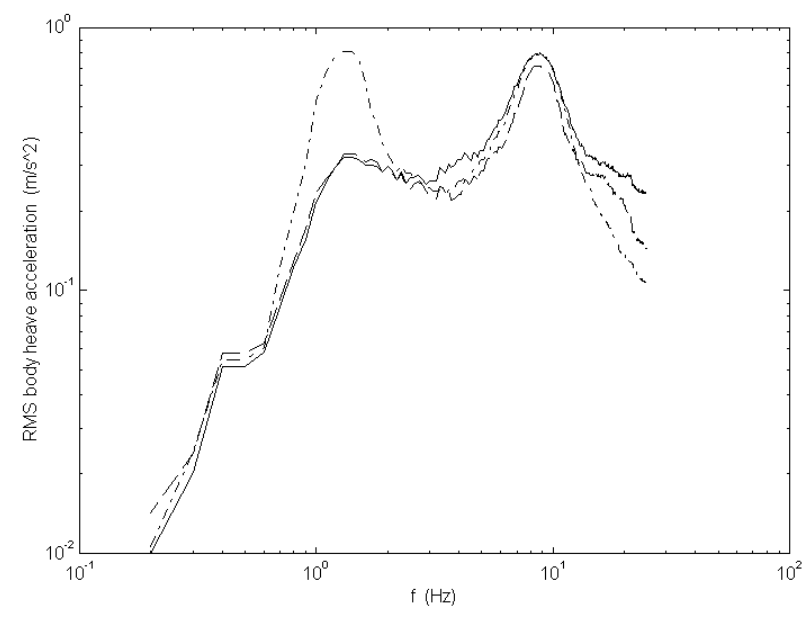

(b)

Figure 6. RMS of chassis heave acceleration. (a) smooth road; (b) rough road. 


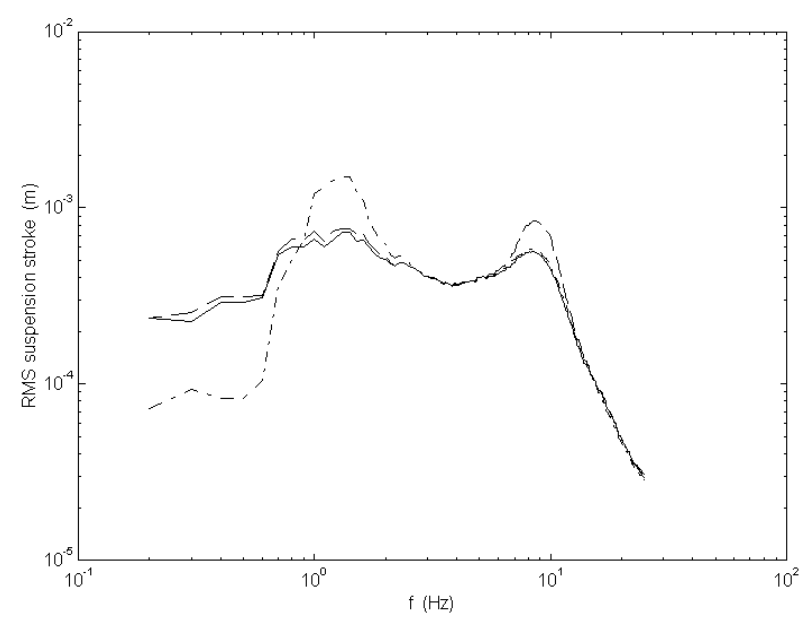

(a)

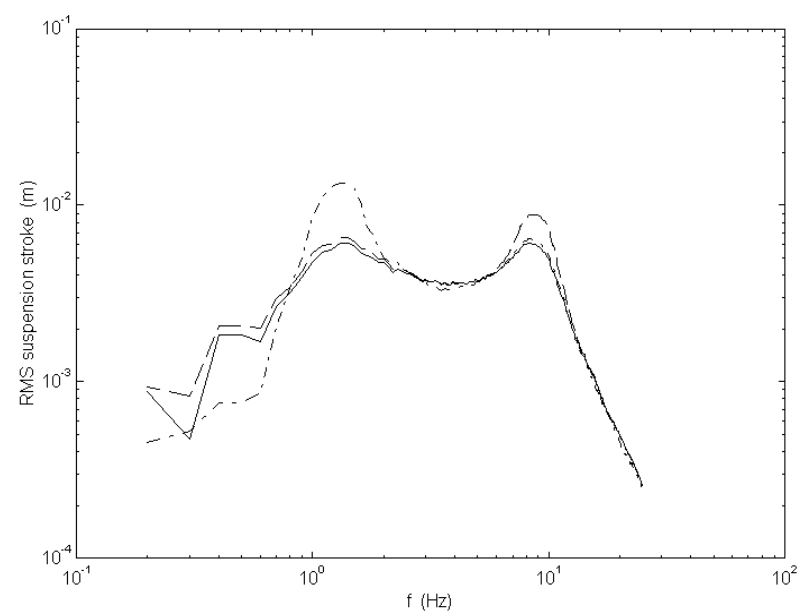

(b)

Figure 7. RMS of suspension stroke. (a) smooth road; (b) rough road.

In this simulation, $B 1_{s k y}$ and $B 2_{s k y}$ have the values of $12,859 \mathrm{Ns} / \mathrm{m}$ and $1440 \mathrm{Ns} / \mathrm{m}$, respectively. These values were determined by the trial-and-error steps described in Section 2 to have a lower chassis acceleration, tire force variation, and suspension stroke with the double sky-hook damper than those with the conventional sky-hook and passive dampers in the sprung and unsprung mass resonant frequency regions. Figures 5-7 show the following characteristics by using the double sky-hook algorithm:

(1) The double sky-hook damper generated better suspension performance than the passive damper for all three performance measures except for slight degradation between the sprung and unsprung mass resonant frequencies, even with increased unsprung mass by the in-wheel motors.

(2) The double sky-hook damper had better road-holding property, as shown in Figure 5, and smaller suspension stroke, as shown in Figure 7, than the conventional sky-hook damper not only in the unsprung mass resonant frequency region, but also in the sprung mass resonant.

(3) The double sky-hook damper had a similar body acceleration as shown in Figure 6 to the conventional sky-hook damper in all frequency regions.

In conclusion, the double sky-hook damper can achieve better a road-holding property, as intended.

\subsection{Full Car Model Simulation}

A full car dynamic model that had eight degrees-of-freedom including roll, pitch, heave, driver seat, and four wheel vertical motions was simulated for more realistic vehicle behavior. Table 2 shows the model parameters of the vehicle under advanced development with in-wheel motors on the rear axle. In order to evaluate the performance variation for the change in damping coefficient, a simulation was performed for the damping coefficients listed in Table 3. Note that the fourth passive damping coefficient in Table 3 was the same as the passive damping coefficient in Table 2. 
Table 2. Model parameters for a full car.

\begin{tabular}{cc}
\hline Parameter & Value \\
\hline Effective weight of front wheel $\left(m_{u f l}, m_{u f r}\right)$ & $54 \mathrm{~kg}$ \\
Effective weight of rear wheel $\left(m_{u r l}, m_{u r r}\right)$ & $68 \mathrm{~kg}$ \\
Weight of sprung mass $\left(m_{s}\right)$ & $1754 \mathrm{~kg}$ \\
Pitch moment of inertia $\left(J_{\phi}\right)$ & $3012 \mathrm{~kg} \mathrm{~m}{ }^{2}$ \\
Roll moment inertia $\left(J_{\theta}\right)$ & $598 \mathrm{~kg} \mathrm{~m}{ }^{2}$ \\
Front axle location from C.G. $\left(L_{f}\right)$ & $1.44 \mathrm{~m}$ \\
Rear axle location from C.G. $\left(L_{r}\right)$ & $1.56 \mathrm{~m}$ \\
Left/Right side from C.G. $\left(W_{l}, W_{r}\right)$ & $0.82 \mathrm{~m}$ \\
Front spring stiffness & $24,426 \mathrm{~N} / \mathrm{m}$ \\
Rear spring stiffness & $31,954 \mathrm{~N} / \mathrm{m}$ \\
Front passive damper coefficient $($ effective) & $1400 \mathrm{Ns} / \mathrm{m}$ \\
Rear passive damper coefficient $($ effective) & $2000 \mathrm{Ns} / \mathrm{m}$ \\
Suspension friction & $54 \mathrm{~N}$ \\
Front stabilizer bar stiffness & $19,984 \mathrm{~N} / \mathrm{m}$ \\
Rear stabilizer bar stiffness & $10,204 \mathrm{~N} / \mathrm{m}$ \\
Tire vertical stiffness & $248,000 \mathrm{~N} / \mathrm{m}$ \\
Tire vertical damping coefficient & $322 \mathrm{Ns} / \mathrm{m}$ \\
Weight of driver $\left(m_{d}\right)$ & $65 \mathrm{~kg}$ \\
Driver's seat stiffness & $10,507.1 \mathrm{~N} / \mathrm{m}$ \\
Driver's seat damping coefficient & $875.6 \mathrm{Ns} / \mathrm{m}$ \\
\hline
\end{tabular}

Table 3. Damping coefficients.

\begin{tabular}{|c|c|c|c|c|}
\hline \multirow[t]{2}{*}{ No. } & \multicolumn{2}{|c|}{$\begin{array}{l}\text { Passive Damping } \\
(\mathrm{Ns} / \mathrm{m})\end{array}$} & \multirow{2}{*}{$\begin{array}{c}\text { Sky-Hook } \\
\text { Algorithm } \\
B 1_{\text {sky }}(\mathrm{Ns} / \mathrm{m})\end{array}$} & \multirow{2}{*}{$\begin{array}{c}\text { Double Sky-Hook } \\
\text { Algorithm } \\
B 2_{s k y}(\mathrm{Ns} / \mathrm{m})\end{array}$} \\
\hline & Front & Rear & & \\
\hline 1 & 560 & 800 & 5000 & 500 \\
\hline 2 & 840 & 1200 & 10,000 & 1000 \\
\hline 3 & 1120 & 1600 & 40,000 & 1500 \\
\hline 4 & 1400 & 2000 & 100,000 & 2000 \\
\hline 5 & 1680 & 2400 & $1,000,000$ & 2500 \\
\hline 6 & 1960 & 2800 & - & - \\
\hline
\end{tabular}

Figures 8-10 show the cross plots for the RMS driver seat heave, chassis pitch, and chassis roll accelerations against RMS tire normal force variation (road-holding performance), respectively. The performance measures were frequency-weighted performance indices computed by multiplication of frequency-weighted curves (Figures 11 and 12) as suggested by ISO2631 [7] with RMS heave, pitch, and the value of roll accelerations and RMS tire normal force variation. The RMS values were calculated using $1 / 3$ octave band frequencies of frequency responses, which were obtained from the time-domain simulation of the full car dynamics model with nonlinearities over the road conditions described in the simulation conditions. In the figures, the solid line denotes the double sky-hook case, the dashed line denotes the conventional sky-hook, and the dash-dot line represents a passive damper. The numbers in each plot correspond to the different damping coefficients listed in Table 3. Note that in the case of the double sky-hook algorithm, the value of $B 1_{\text {sky }}$ was fixed to the value of $10,000 \mathrm{Ns} / \mathrm{m}$ and the simulation was performed for the values of $B 2_{\text {sky }}$ from zero (this point in Figures 8-10 is point 2 in the conventional sky-hook algorithm) to the values in Table 3. 


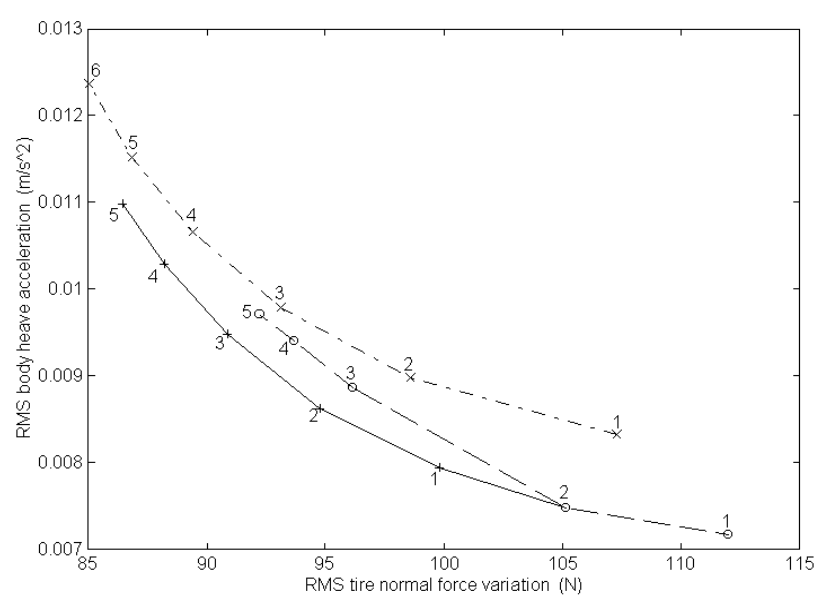

Figure 8. Tire normal force variation vs. heave acceleration.

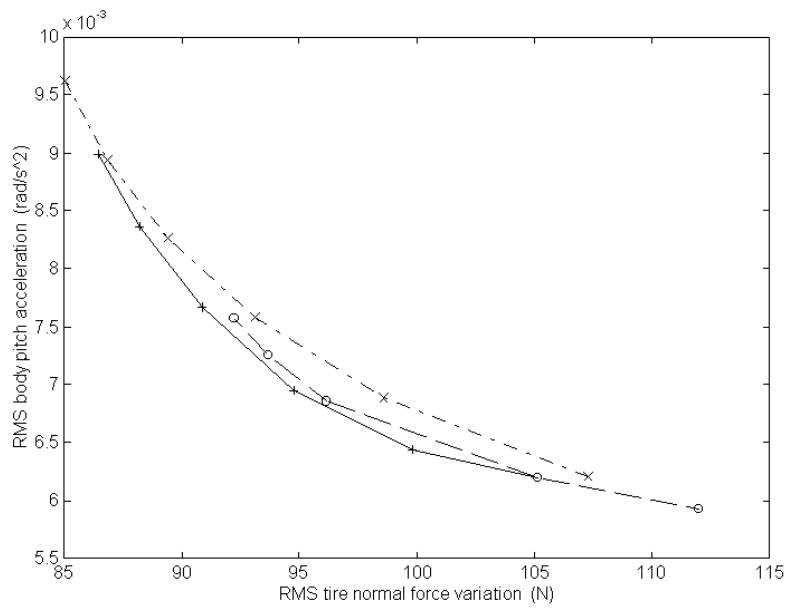

Figure 9. Tire normal force variation vs. pitch acceleration.

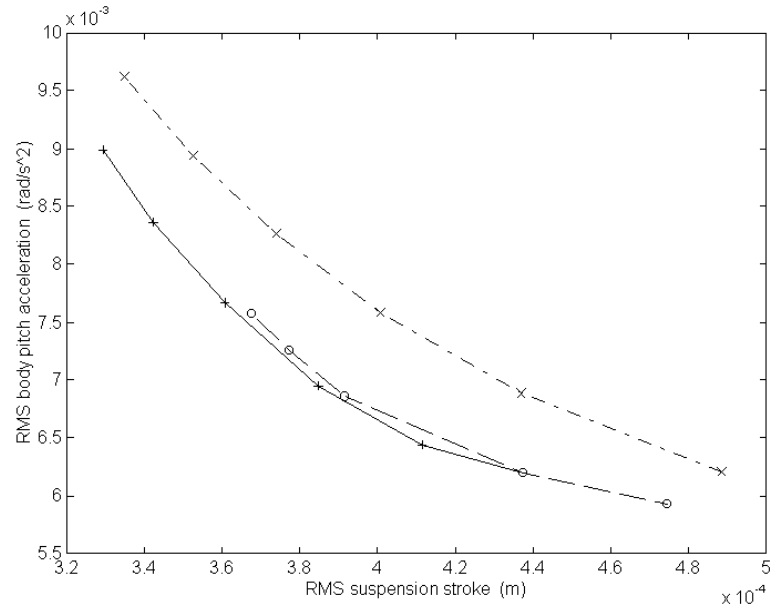

Figure 10. Tire normal force variation vs. roll acceleration. 


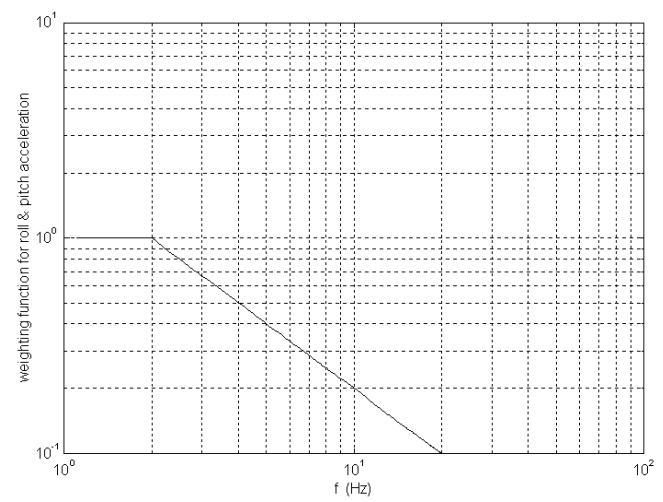

Figure 11. Frequency weighting function for roll and pitch acceleration.

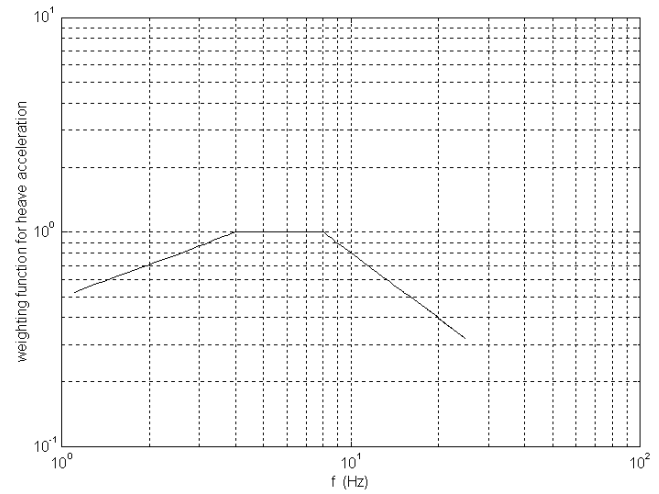

Figure 12. Frequency weighting function for heave acceleration.

Figures 8-10 show the following characteristics:

(1) The double sky-hook damper had smaller RMS seat accelerations and smaller RMS tire normal force variation than the passive and conventional sky-hook dampers, even in the development vehicle with in-wheel motors.

(2) In the case of the conventional sky-hook damper, the performance indices converged to the vicinity of a certain point (e.g., number 5 in the plots) as $B 1_{s k y}$ was increased close to infinity. This means that the conventional sky-hook damper cannot generate better road-holding performance than the passive damper. In the meantime, the double sky-hook damper could achieve better road-holding performance and ride quality than a passive damper.

(3) The sky-hook damping parameter at unsprung mass of double sky-hook damper provided tuning freedom to improve tire normal force variation while minimizing deterioration in seat acceleration. Therefore, the parameter was used to differentiate the driving mode of the vehicle under advanced development, as shown in Table 4.

Table 4. Drive mode differentiation of the development vehicle.

\begin{tabular}{cc}
\hline Driving Mode & $\mathbf{B 2}_{\text {sky }} \mathbf{( N s / m )}$ \\
\hline Comfort mode & 0 \\
Normal mode & 500 \\
Sports mode & 1500 \\
Racing track mode (Hyundai $N$ mode) & 2000 \\
\hline
\end{tabular}

\section{Conclusions and Discussion}

A double sky-hook algorithm for application to in-wheel motored vehicle has been presented. It was proven that the double sky-hook algorithm could achieve a higher level 
of compromise for road-holding and ride comfort compared to not only passive suspension, but also conventional sky-hook suspension.

Even in the development vehicle with in-wheel motors, the double sky-hook damper for a semi-active suspension system could improve the vehicle dynamic stability and reduce suspension travel distance while maintaining a better ride comfort than the passive and the conventional sky-hook dampers could generate. The smaller suspension travel also reduced the noise and vibration transmitted to the chassis.

The sky-hook damping parameter at unsprung mass of double sky-hook damper provided tuning freedom to improve vehicle dynamic stability while minimizing deterioration in ride quality. This paper also proposed the parameter set of the double sky-hook algorithm to differentiate the driving mode of the in-wheel motored vehicle under development.

The advanced development vehicle using the proposed algorithm is currently in the virtual development stage. Therefore, implementation, tests, and evaluation of the double sky-hook algorithm for in-wheel motored vehicles are the topics of our future research. For comparison with the simulation results, it is necessary to secure the reliability and repeatability of the test, so not only the actual vehicle test, but also the equipment test will be conducted as shown in Figure 13. The Hyundai Motor Company is expanding the scope of virtual development by performing these tasks.

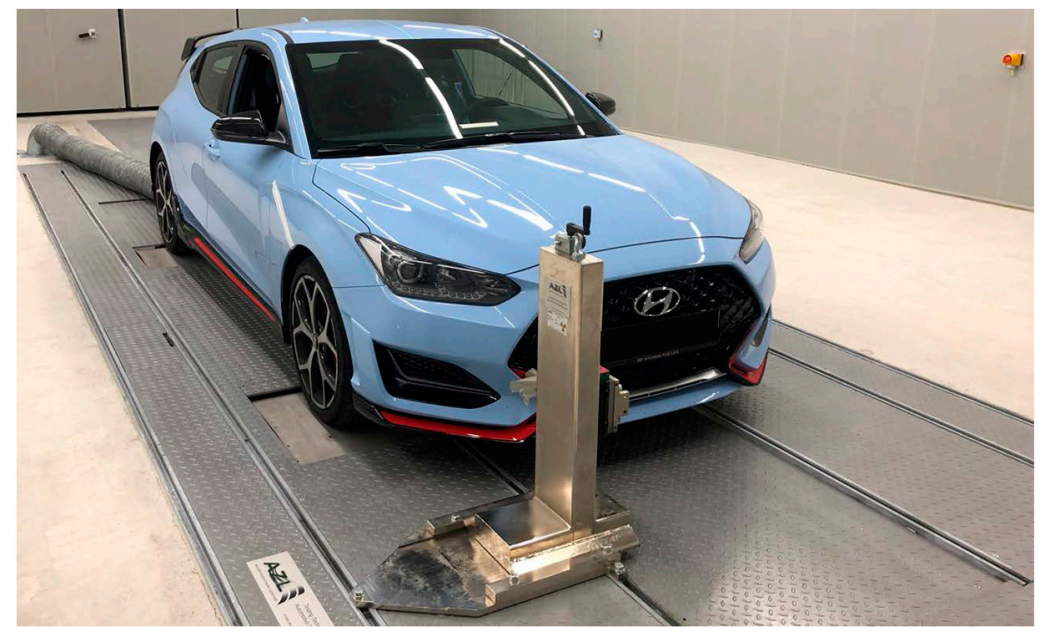

Figure 13. Roller bench test rig to secure the reliability and repeatability of the ride comfort test.

For electric vehicles currently under development, due to the weight of the motor and battery, not only the unsprung mass but also the sprung mass is large, therefore algorithms such as the acceleration driven damper, which functions similar to the technology mainly applied to light racing cars, were not considered. In the future, in preparation for a weight reduction in electric vehicles, we plan to conduct mass-production application studies on algorithms to reduce the vibration acceleration of light vehicles.

Author Contributions: Conceptualization, D.S. and S.W.; Methodology, D.S.; Software, D.S.; Validation, D.S. and S.W.; Formal analysis, D.S.; Investigation, S.W.; Resources, D.S.; Data curation, S.W.; Writing-original draft preparation, D.S.; Writing—review and editing, S.W.; Visualization, D.S.; Supervision, S.W.; Project administration, S.W.; Funding acquisition, S.W. Both authors have read and agreed to the published version of the manuscript.

Funding: This paper was supported by a National Research Foundation of Korea (NRF) grant funded by the Korean government (MSIT; No. 2021R1F1A1048133) and by the Sookmyung Women's University Research Grants (1-2103-1077).

Institutional Review Board Statement: Not applicable.

Informed Consent Statement: Not applicable. 
Data Availability Statement: Not applicable.

Conflicts of Interest: The authors declare no conflict of interest.

\section{Appendix A}

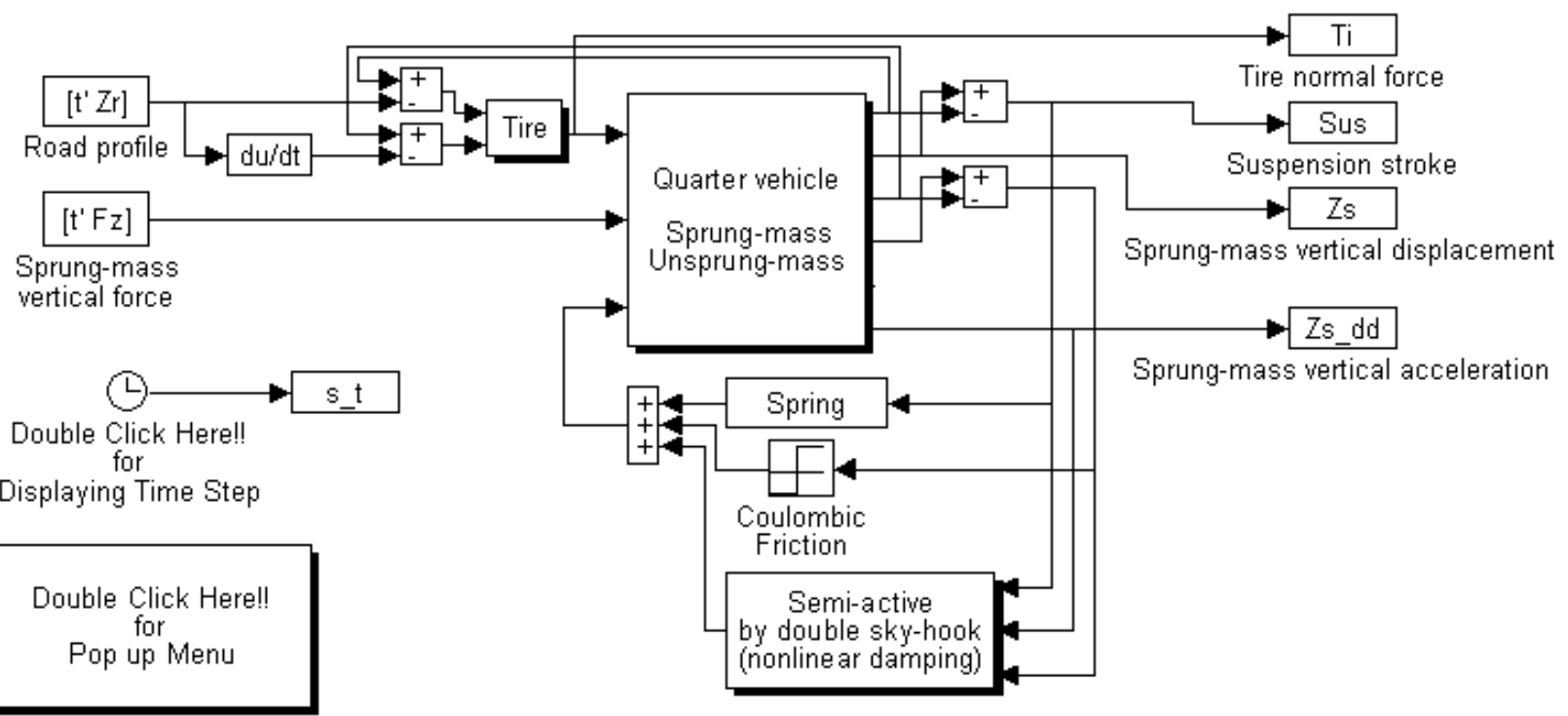

Figure A1. Quarter car model using the simulation modules.

$$
\begin{aligned}
& \mathrm{m}_{\mathrm{u}} \ddot{z}_{\mathrm{u}}-\mathrm{f}_{\mathrm{s}}+\mathrm{f}_{\mathrm{t}}=0 \\
& \mathrm{~m}_{\mathrm{s}} \ddot{z}_{\mathrm{s}}+\mathrm{f}_{\mathrm{s}}=\mathrm{f}_{\mathrm{z}}
\end{aligned}
$$

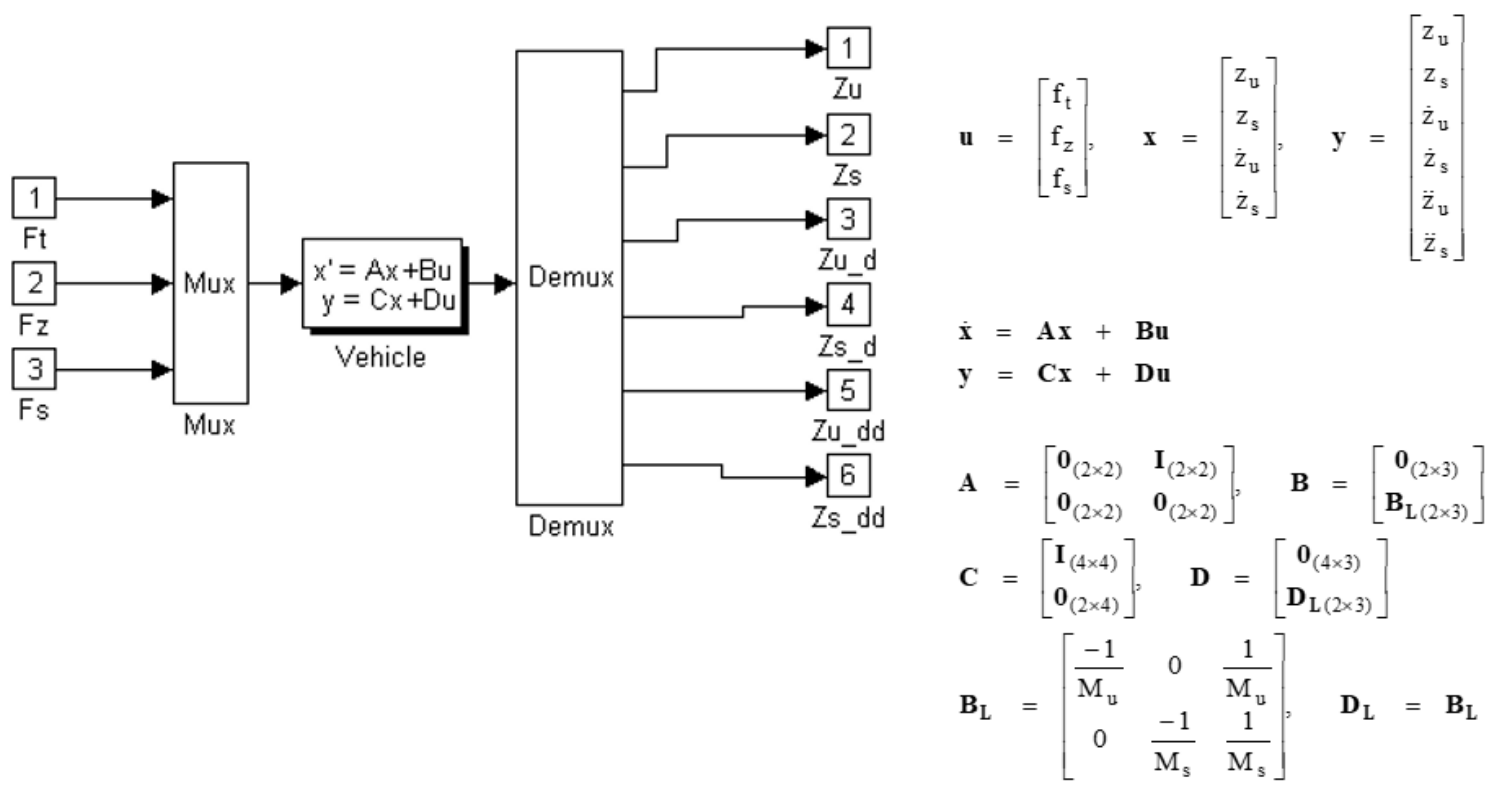

Figure A2. Quarter car body module. 


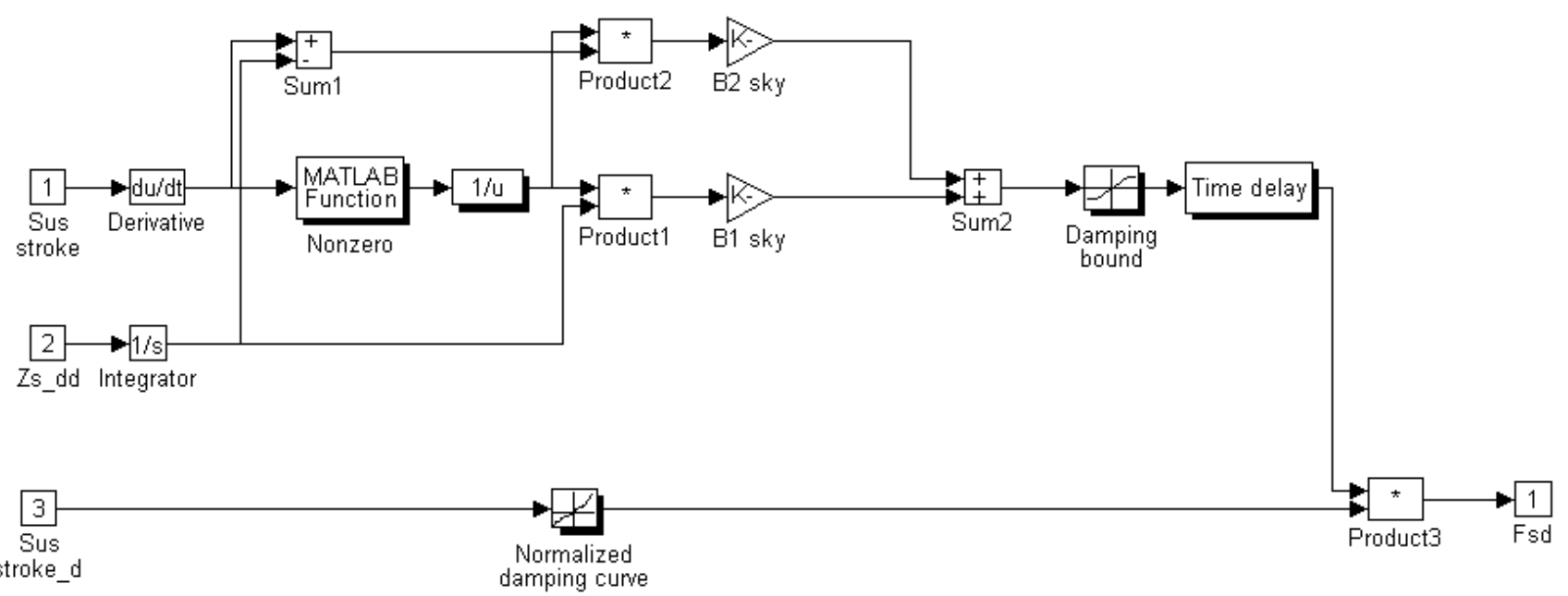

Figure A3. Semi-active control module using the continuous double sky-hook algorithm with a nonlinear damper.

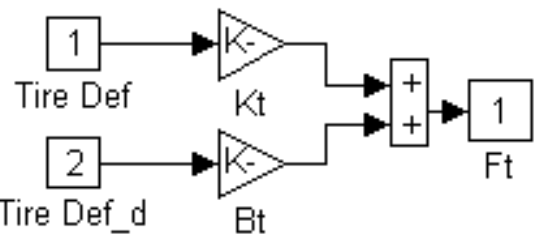

Figure A4. Tire module.

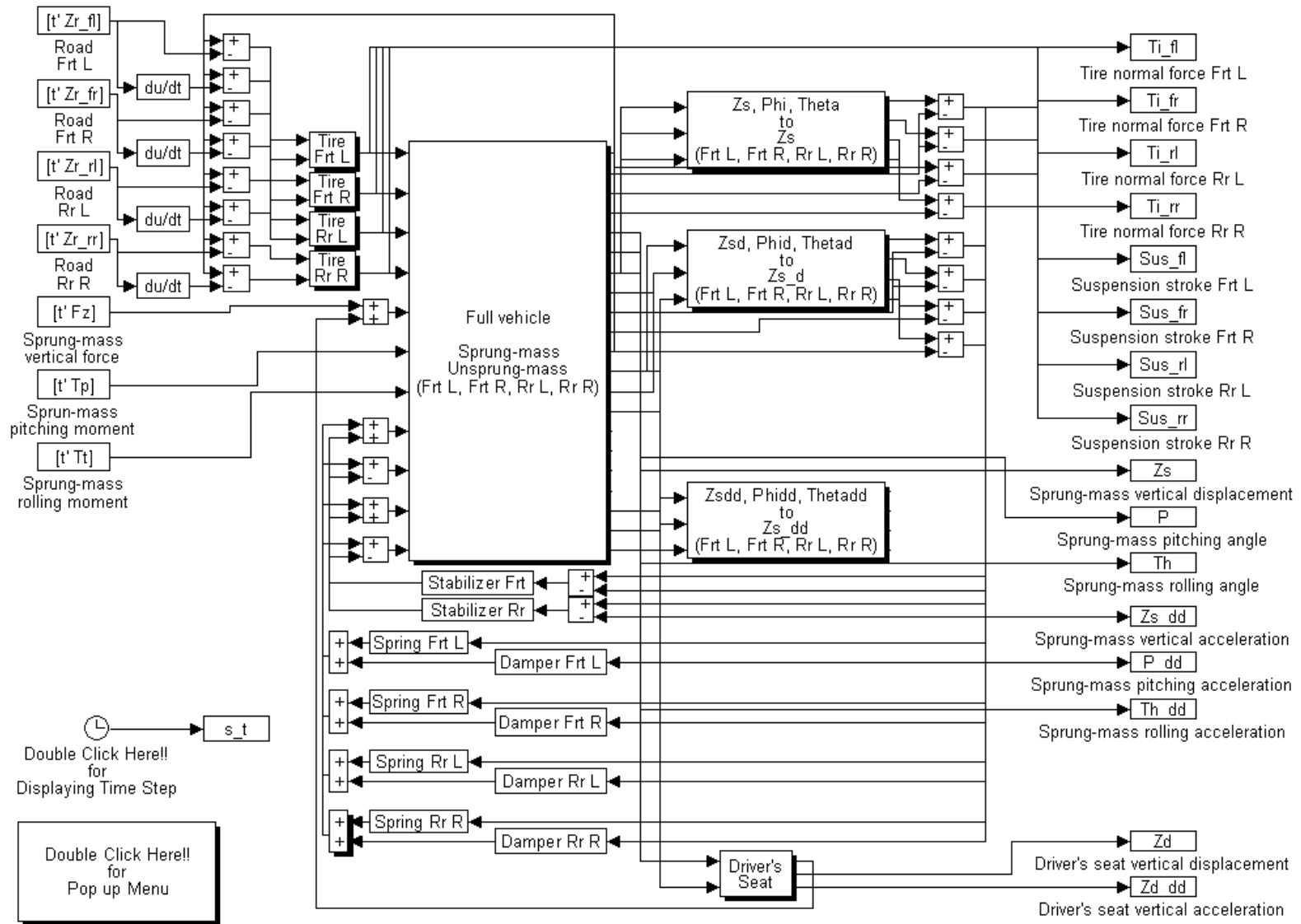

Figure A5. Full car model using the simulation modules. 


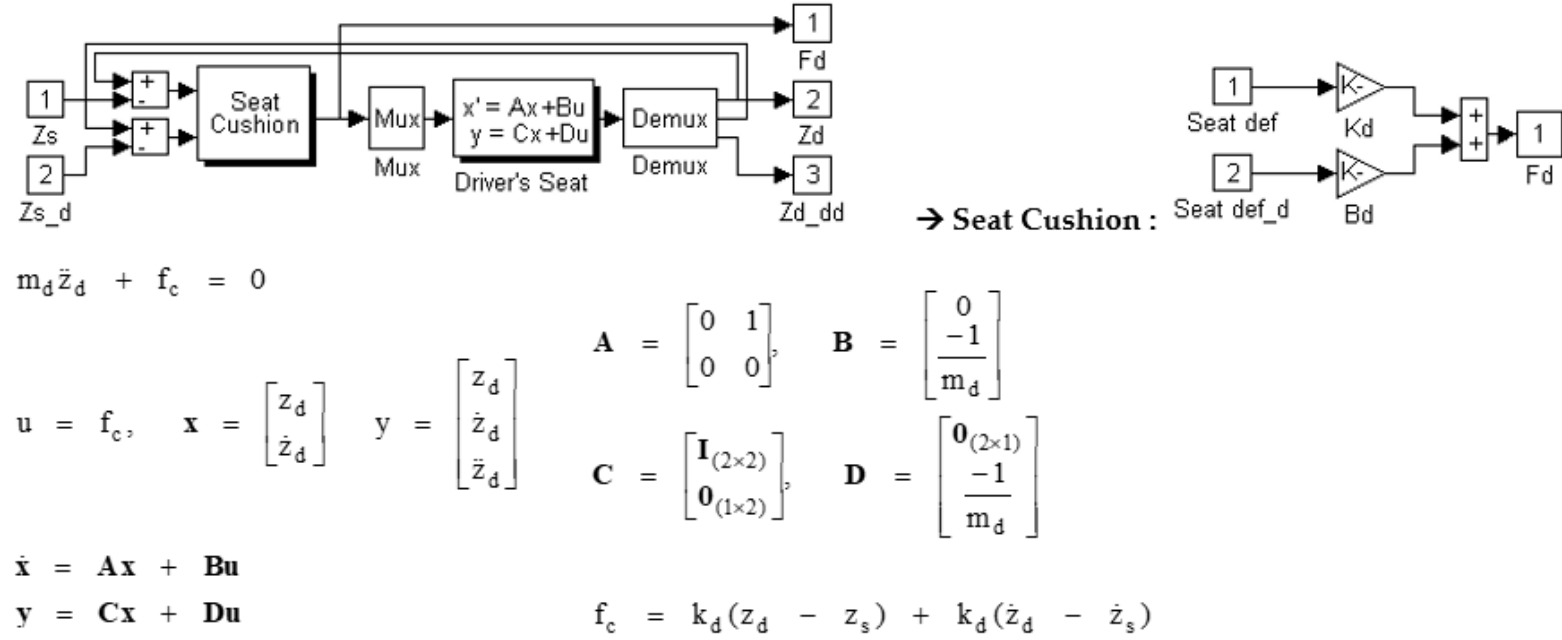

Figure A6. Driver's seat module.

\section{References}

1. Wu, F.-K.; Yeh, T.-J.; Huang, C.-F. Motor Control and Torque Coordination of an Electric Vehicle Actuated by Two In-Wheel Motors. Mechatronics 2013, 23, 46-60. [CrossRef]

2. Murata, S. Innovation by In-Wheel-Motor Drive Unit. Veh. Syst. Dyn. 2012, 50, 807-830. [CrossRef]

3. Crolla, D. Automotive Engineering: Powertrain, Chassis System and Vehicle Body; ELSEVIER: Amsterdam, The Netherlands, 2009.

4. Kobayashi, T.; Katsuyama, E.; Sugiura, H.; Ono, E.; Yamamoto, M. Direct Yaw Moment Control and Power Consumption of In-Wheel Motor Vehicle in Steady-State Turning. Veh. Syst. Dyn. 2017, 55, 104-120. [CrossRef]

5. Wang, Q.; Zhao, Y.; Deng, Y.; Xu, H.; Deng, H.; Lin, F. Optimal Coordinated Control of ARS and DYC for Four-Wheel Steer and in-Wheel Motor Driven Electric Vehicle with Unknown Tire Model. IEEE Trans. Veh. Technol. 2020, 69, 10809-10819. [CrossRef]

6. Anderson, M. Unsprung Mass with In-Wheel Motors-Myths and Realities. Proc. AVEC 2010, 10, 261-266.

7. Du, H.; Sze, K.Y.; Lam, J. Semi-Active Ho Control of Vehicle Suspension with Magneto-Rheological Dampers. J. Sound Vib. 2005, 283, 981-996. [CrossRef]

8. Gu, X.; Yu, Y.; Li, J.; Li, Y. Semi-Active Control of Magnetorheological Elastomer Base Isolation System Utilising Learning-Based Inverse Model. J. Sound Vib. 2017, 406, 346-362. [CrossRef]

9. Jansen, L.M.; Dyke, S.J. Semiactive Control Strategies for MR Dampers: Comparative Study. J. Eng. Mech. 2000, 126, 795-803. [CrossRef]

10. Karnopp, D.; Crosby, M.J.; Harwood, R.A. Vibration Control Using Semi-Active Force Generators. J. Manuf. Sci. Eng. 1974, 96, 619-626. [CrossRef]

11. Anaya-Martinez, M.; Lozoya-Santos, J.-J.; Félix-Herrán, L.C.; Tudon-Martinez, J.-C.; Ramirez-Mendoza, R.-A.; Morales-Menendez, R. Control of Automotive Semi-Active MR Suspensions for in-Wheel Electric Vehicles. Appl. Sci. 2020, 10, 4522. [CrossRef]

12. Basargan, H.; Mihály, A.; Gáspár, P.; Sename, O. Adaptive Semi-Active Suspension and Cruise Control through LPV Technique. Appl. Sci. 2021, 11, 290. [CrossRef]

13. Emura, J.; Kakizaki, S.; Yamaoka, F.; Nakamura, M. Development of the Semi-Active Suspension System Based on the Sky-Hook Damper Theory. SAE Trans. 1994, 103, 1110-1119.

14. Venhovens, P.T. The Development and Implementation of Adaptive Semi-Active Suspension Control. Veh. Syst. Dyn. 1994, 23, 211-235. [CrossRef]

15. Williams, R.A. Electronically Controlled Automotive Suspensions. Comput. Control Eng. J. 1994, 5, 143-148. [CrossRef]

16. Palkovics, L.; Bokor, J.; Venhovens, P. Design Problems of the Semi-Active Wheel Suspension System and a Possible Way of Their Elimination. In Proceedings of the FISITA'94 World Congress, Beijing, China, 17-21 October 1994.

17. Kim, H. A Study for the Control of Passenger Car Suspension for Ride Comfort. Ph.D. Thesis, KAIST, Daejeon, Korea, 1994.

18. Woo, S.; Ryu, J.H. Design of Double Sky-hook Algorithm for Semi-active Suspension System. In Proceedings of the KSAE 1996 Annual Autumn Conference, Seoul, Korea, 30 November 1996.

19. Goncalves, F.D.; Ahmadian, M. A Hybrid Control Policy for Semi-Active Vehicle Suspensions. Shock Vib. $2003,10,59-69$. [CrossRef]

20. Ren, H.; Zhao, Y.; Chen, S.; Liu, G. State Observer Based Adaptive Sliding Mode Control for Semi-Active Suspension Systems. J. Vibroeng. 2015, 17, 1464-1475.

21. Geng, G.; Yu, Y.; Sun, L.; Li, H. Research on Ride Comfort and Driving Safety under Hybrid Damping Extension Control for Suspension Systems. Appl. Sci. 2020, 10, 1442. [CrossRef]

22. Wong, J.Y. Theory of Ground Vehicles; John Wiley \& Sons: Hoboken, NJ, USA, 2008. 